\title{
The Power of Social Media on Esthetic Dental Treatment Choices in Arabian Gulf Region
}

\author{
Amal S Al Awdah ${ }^{1 *}$, Bashayer Bani Ali², Shams Al Twaim² and Alhanouf A Al Habdan ${ }^{1}$ \\ ${ }^{1}$ Department of Restorative Dental Sciences, College of Dentistry, King Saud University, Riyadh, KSA \\ ${ }^{2}$ BDS, College of Dentistry, King Saud University, Riyadh, KSA
}

*Corresponding author: Amal S Al Awdah, Lecturer, Department of Restorative Dental Sciences, College of Dentistry, King Saud University, P.O. Box 54236, Riyadh 11415, KSA, Tel: +966504401330; E-mail: dramal@gmail.com

Received: 25 Oct, 2018 | Accepted: 05 Nov, 2018 | Published: 09 Nov, 2018

Citation: Al Awdah AS, Ali BB, Al Twaim S, Al Habdan AA (2018) The Power of Social Media on Esthetic Dental Treatment Choices in Arabian Gulf Region. Int J Dent Oral Health 5(1): dx.doi.org/10.16966/2378-7090.280

Copyright: (C) 2018 Al Awdah AS, et al. This is an open-access article distributed under the terms of the Creative Commons Attribution License, which permits unrestricted use, distribution, and reproduction in any medium, provided the original author and source are credited.

\begin{abstract}
Objective: To evaluate the impact of social media on the patient's choice of dental esthetic treatment in the Arabian Gulf region.

Materials and Methods: This cross-sectional study was conducted on 2015 and finished on 2015. One thousand twenty-eight online and paperbased questionnaires were answered regarding four main domains. i. The first is the demographic data, education, nationality, and whether or not the participant had an active account in any social media sites. ii. The pervasiveness of using social media sites as a reliable source of information about dental esthetic: treatment options, clinics, and practitioners. iii. The effect of esthetic dental clinic advertisements on the patient's willingness to visit and the promotion of a certain esthetic dental professional. iv. Lastly, the influence of the families, friends, and celebrities on the patient's choice about certain dental esthetic: treatment, clinics, and practitioners.
\end{abstract}

Results: Most of the participants (98.3\%) have at least one account on the social media network, and $81.6 \%$ of them use their accounts daily. Nearly two thirds of the sample tends to get their dental information from social networking $(66.2 \%)$, and about $45 \%$ are affected by their families and friends in regard to their dental esthetic treatment choice.

Conclusion: Social media has proven to have a powerful effect in Saudi Arabia and the Arabian Gulf region. Participants tend to seek dental information, follow, and communicate with dentists, and write about their dental experience through social media.

Keywords: Social media; Social networking; Trends; Dental practice; Arabian Gulf

\section{Introduction}

Social media is the platform by which information and ideas can be created and shared using online networks and virtual $[1,2]$ people can communicate instantly using social media applications available in their smart phones. These applications allow each person to have his or her own personal account where he or she can have the opportunity to share information, pictures, thoughts, ideas, etc. One can also express his or her opinion freely and discuss multiple topics that they are interested in. The most popular social media tools worldwide are Facebook, YouTube, Twitter, LinkedIn, and Instagram, but the technology is constantly evolving, and there are many more available [3].

The population in the Middle East was estimated to be 230 million, and approximately 103 million of them had access to the Internet, representing about $45 \%$ of the overall population [4]. In addition, about 23 million of the Internet users were Facebook subscribers, thus involved in social media sites. According to the Internet World Stats, the number of estimated Internet users in the Arabian Gulf region population is considered highly significant since June 30, 2014 [4]. Saudi Arabia represents the highest statistics in social media users in the Arabian Region [4]. The popularity of social media has been boosted by the high rate of Smartphone ownership [5]. In Saudi Arabia, the most used social media applications according to the statistical portal in 2014 was Whatsapp, followed by Facebook, Twitter, and then Google+ [6].

The power of social media and its effect on esthetic dental treatment choices should not be underestimated. Many dentists neglect the use of social media in their clinics. They may neglect the thought of using social media to add a value to their dental marketing or it has an effect on the patient's feedback after the esthetic dental treatment. However, the overgrowth of social media over the past few years showed that 
this domain should be used with the increased demand for esthetic dentistry [7]. A study investigated the impact of popular media on cosmetic dentistry. They found that popular media had an impact on the demand for various esthetic dental procedures affecting mainly tooth whitening and veneers [8]. It has been anticipated that dentists will continue to experience a growth in demand for esthetic dental treatment because of patients' desires for better-looking smiles [9].

Because of the rising era of social media, this study is aimed to investigate the manner in which social media sites have affected the choices patients make regarding dental esthetic: treatment, clinics, and practitioners in the Arabian Gulf region and especially in the Kingdom of Saudi Arabia.

\section{Materials and Methods}

This is a cross-sectional study with self-administered paperbased and online-electronic questionnaires. The questions were selfdeveloped; then a pilot study was conducted, and the questions were adjusted accordingly. The study was conducted on 2015 and finished on 2015. Informed consent and the rationale of the survey were noted in the first page of the written and online version of the questionnaires. Only subjects who were under 18 years old were not included in this study. One thousand paper-based questionnaires were distributed through multiple hospitals and shopping malls in Riyadh, Saudi Arabia. The online questionnaires' link was constructed using survey monkey ${ }^{\circ}$ (www.surveymonkey.com) and posted several times through multiple social media sites such as Twitter, Instagram, Whatsapp, and E-mails. This study was approved by the ethics committee of the College of Dentistry Research Center, Deanship of Scientific Research, $\mathrm{KSU}$ and was conducted following the ethical guidelines of the Declaration of Helsinki.

The questionnaire was conducted in the Arabic language and was self-administered; it consisted of four main sections. i. The first was about demographic data, educational background, nationality, and whether or not the participant had an active account in any social media site. ii. To evaluate the pervasiveness of using social media sites as a reliable source of information about dental esthetic: treatment options, clinics, and practitioners. iii. The effect of esthetic dental clinic social media advertisements on the patient's willingness to visit and the promotion of a certain esthetic dental professional by posting his or her work on social media sites and its effect on patients. iv. The influence of the families, friends, and celebrities on the patient's choice of certain dental esthetic: treatment, clinics, and practitioners.

All the paper-based and online responses were entered into an electronic database and analyzed using the Statistical Package for Social Sciences (Version 22.0; www.spss.com). Frequency distribution was used for descriptive analysis of the data. Chisquared test at $5 \%$ significance was used for the statistical relationship between variables.

\section{Results}

One thousand twenty-eight subjects responded to this study from written and online forms. Fifty-three percent of this sample was from Saudi Arabia, whereas $47 \%$ of the participants are from other Gulf countries. The most responded age group was $26-45$ years old, which made up $(46.5 \%)$ of the total participants. The majority were females (87.3\%) with a bachelor's degree (65.1\%). Most of the participants have at least one account on social media networks (98.3\%), and $81.6 \%$ of them use their accounts daily table 1.
Table 1: Distribution of sociodemographic characteristics of study subjects $(n=1028)$

\begin{tabular}{|c|c|}
\hline Variables & No. (\%) \\
\hline \multicolumn{2}{|c|}{ Age (in years) } \\
\hline $18-25$ & $466(45.3)$ \\
\hline $26-45$ & $478(46.5)$ \\
\hline $46-65$ & $84(8.2)$ \\
\hline \multicolumn{2}{|c|}{ Gender } \\
\hline Male & $131(12.7)$ \\
\hline Female & $897(87.3)$ \\
\hline \multicolumn{2}{|l|}{ Nationality } \\
\hline Saudi & $545(53)$ \\
\hline Other Gulf countries & $483(47)$ \\
\hline \multicolumn{2}{|c|}{ Level of Education } \\
\hline Middle school & $41(4)$ \\
\hline High school & $170(16.5)$ \\
\hline Bachelor & $669(65.1)$ \\
\hline Master & $118(11.5)$ \\
\hline Ph.D & $30(2.9)$ \\
\hline \multicolumn{2}{|c|}{ Do you have an account on any of the social media sites? } \\
\hline No account & $17(1.7)$ \\
\hline Twitter or Instagram or Facebook & $245(23.8)$ \\
\hline Any 2 accounts & $375(36.5)$ \\
\hline All the 3 accounts & $391(38.0)$ \\
\hline \multicolumn{2}{|c|}{ Frequency of account use } \\
\hline Everyday & $839(81.6)$ \\
\hline Once a week & $35(3.4)$ \\
\hline Once a month & $16(1.6)$ \\
\hline Sometimes & $106(10.3)$ \\
\hline Rarely & $32(3.1)$ \\
\hline
\end{tabular}

The distribution and comparison of responses toward dental esthetic treatment choices with an influence of social media is demonstrated in table 2. More than half of the subjects (53.4\%) were following a dentist or a dental clinic on social media sites, and they significantly $(\mathrm{P}<0.0001)$ thought that dentists should communicate with people through social media rather than conventional media (91\%). When comparing age groups, those between the ages of 18-25 years old constitute the majority of followers (64.2\%); this age group also appreciated the presence and communication with dentists on social media sites (92.8\%). Additionally, most of the subjects with higher education including a bachelor's or master's degree thought that dentists should communicate with people through social media rather than conventional media. Most participants (66.2\%) significantly referred that if they needed to get information about an esthetic dental treatment or clinic, social media will be the first source for information $(\mathrm{P}<0.0001)$. Females $(67.8 \%)$ strongly tend to acquire dental information from social media compared with their male counterparts $(\mathrm{P}=0.008)$. Regarding education, most of the subjects who referred to social media as the first choice of information are those with high school level of education. Almost half of the subjects $(55 \%)$ trusted the information on social media about dentists and dental clinics $(\mathrm{P}=0.001)$.

Looking at the reliability of advertisements for esthetic treatment, most subjects (45.5\%), and especially those between the age of 26-45 
Table 2: Distribution and comparison of responses toward the Distribution and Comparison of Responses towards Dental Esthetic Treatment Choices with an Influence of Social Media.

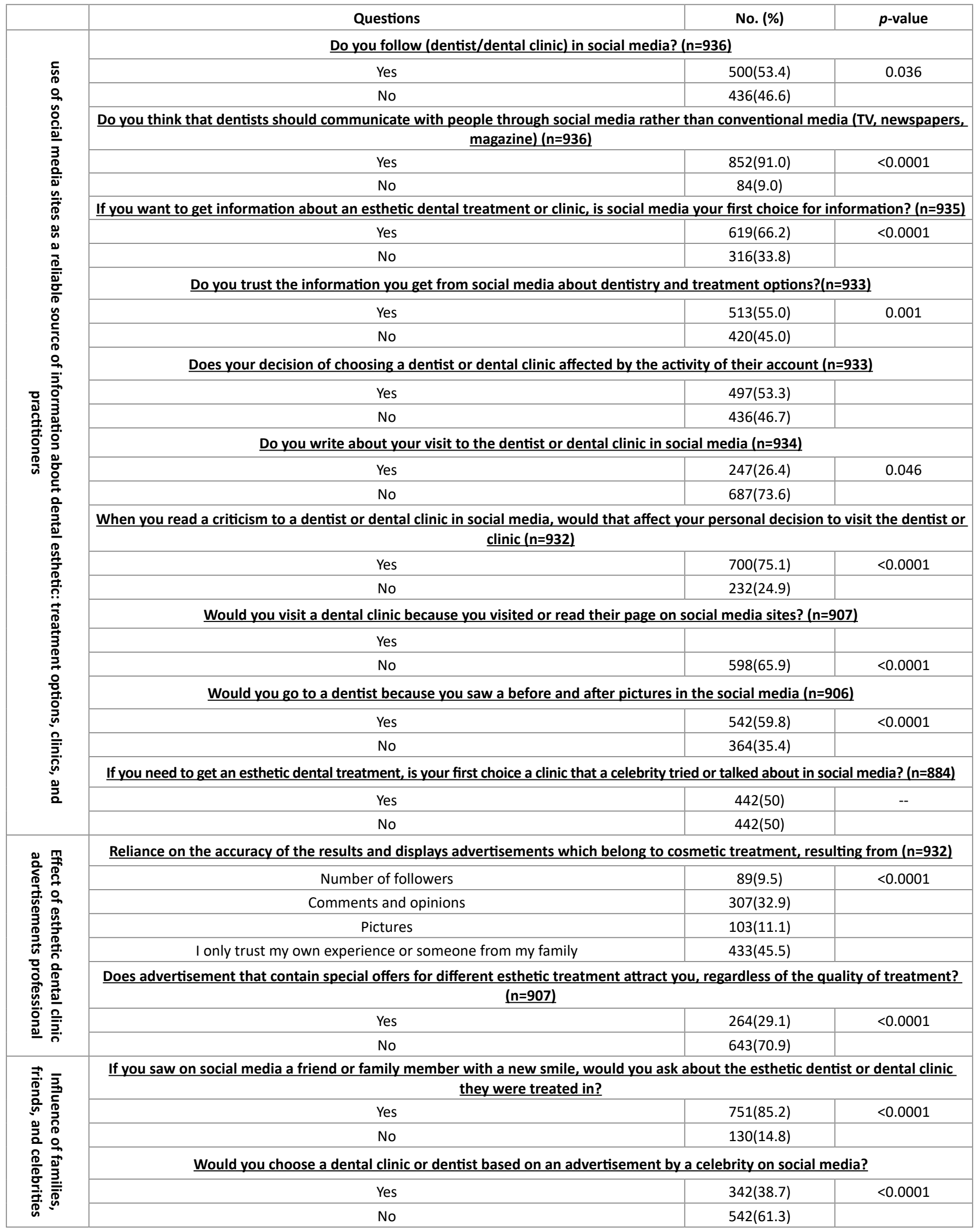


years (47.8\%) relied on their own experience, followed by comments and opinions on social media (32.9\%), then pictures posted about the esthetic cases $(11.1 \%)$, and lastly by the number of followers of the dentist or the dental clinic (9.5\%).

The participants were significantly $(\mathrm{P}=0.046)$ affected when choosing a dentist or a dental clinic by their account activity on social media (53.3\%). A significant number of subjects (73.6\%) also tend to write about their visit to the dentist or dental clinic $(\mathrm{P}<0.0001)$. On the other hand, for majority of subjects $(75.1 \%)$ reading criticism of a dentist or dental clinic significantly will affect the subjects' decision to visit that dentist or dental clinic $(\mathrm{P}<0.0001)$.

The majority of the subjects (65.9\%) would visit a dental clinic because they viewed or read their page on social media sites $(\mathrm{P}=0.0001)$. Also, $59.8 \%$ of the subjects would go to a dentist because they saw before and after pictures in social media sites $(\mathrm{P}<0.0001)$. When comparing age groups, the age group 18-25 years was significantly $(\mathrm{P}=038)$ affected by before and after pictures $(64 \%)$.

A significant number of subjects (70.9\%) were not attracted by advertisement with special offers for different esthetic treatment, regardless of the quality of treatment $(\mathrm{P}<0.0001)$. Looking closer at the level of education, subjects with a $\mathrm{PhD}$ were the least affected by the advertisement. Also, advertisement had less effect on females compared with males. There was no considerable effect of celebrity's advertisement on social media about esthetic dental treatment. On the other hand, (85.2\%) of the subjects, especially females (87.1) would ask a friend or family member with a new smile on social media about their dentist or dental clinic $(\mathrm{P}<0.0001)$.

\section{Discussion}

Web 2.0 technologies, known as social media or social technologies have emerged into the mainstream of media. As they grow, these new technologies have the opportunity to influence the methods and procedures of many fields [10-13]. The use of social networking media is increasing among healthcare providers and patients as well $[10,14,15]$. This study highlighted this impact of social media in the Arabian Gulf population. Most of the participants in the study have at least one account on the social media network (98.3\%), and $81.6 \%$ of them use their accounts daily, which might give an indication that social media has a strong effect on different aspects of their lives.

In the present study, it was noticed that there was no significant difference between the responses given by Arabian Gulf countries regarding the use of social media. This might be due to the similar environmental, cultural, and religious backgrounds $[6,16]$. Most of the respondents were females (87.3\%). Pew Research Center's Internet and American Life Project's tracking surveys found that among Internet users, women are significantly more likely than men to use social media sites [17].

The highest age group that responded to the survey is $26-45$ years old. This age group usually are employed, and according to a report done by Pew Research Center "Technology's Impact on Workers," $53 \%$ of Internet users are employed full time or part time, in positions ranging from executive to business owner to skilled and semiskilled workers [18]. A high percentage of the participants had a bachelor's degree; this comes to agreement with other studies done in Saudi Arabia [19].

More than half of the subjects (53\%) were following a dentist or a dental clinic on social media, and they significantly agree that dentists should communicate with people through social media rather than conventional media $(91 \%)(\mathrm{P}<0.0001)$. This comes in agreement with several western studies where patients appreciated the presence of healthcare providers in the social networks [2,11,20-22]. McNab, et al. point out that this allows them to communicate rapidly and without any filtration [23]. Younger generations of healthcare providers are more active in responding to this demand [14].

The study showed that a significant number of participants would refer to social media to get information about esthetic treatment choices and esthetic dentistry clinics. Almost 55\% of the subjects trusted the information on social media about dentists and dental clinics $(\mathrm{P}<0.0001)$. Worldwide, there is high tendency to get and trust health information from social networking [12-14,24-26]. Hamm, et al. show that a high percentage of people were using the Internet to look for health-related information, and it was the third most common activity when using the Internet [10]. Another survey posted by Pew Research Center in 2013 confirms that $72 \%$ of adult Internet users sought support and medical information online [24].

Participants were asked "what will attract them most to visit a dentist/dental clinic when viewing their sites on social networking"; most chose to trust their own dental experience followed by comments and opinions on social media, then pictures posted about the case, and lastly by the number of followers of the dentist or the dental clinic. This might be attributed to the questioning of the reliability of the dental clinic's advertisements.

When comparing the age groups, 18-25 years were significantly affected by before and after pictures. The young generation tend to use and post videos and pictures in social media more than any other age groups $[27,28]$; this may be the reason why they trust pictures more $[29,30]$.

The majority (75.1\%) of the participants would get affected by written experiences and criticism about dental care on social networking sites, proving the strong impact of social media $[12,15,23]$. The freedom of speech on social media allows patients to comment and write about their experiences, emotions, and evaluation of different treatment modalities. The global social media community is expected to be able to add value to the conversation, to help correct rumors or misinformation, provide feedback, or offer personal experience [23]. Most of the respondents to this survey were affected by their families' and friends' dental experience followed by advertisement and were least affected by celebrities. Fox, et al. found that $68 \%$ of all adults in their study ask a friend or family member about health information [26]. Theobald, et al. studied the demand for esthetic dental treatment and found that there is an increase in demand for dental esthetics, female more than male [8]. The most demanded procedures were whitening and veneers; this increase in demand was noticed following makeover TV shows and women's magazines [8].

This study highlighted the value of communication between the public and dental care providers through social media sites $(\mathrm{P}=0.0001)$. Subjects tended to trust the information presented through social media $(\mathrm{P}=0.011)$. Most respondents active on social media sites would likely get affected by criticism written after dental visits $(\mathrm{P}=0.001)$.

\section{Conclusion}

Social media has proven to have a powerful effect in Saudi Arabia and the Arabian Gulf region. More people are utilizing social media to communicate with dental professionals, search for information, and write about their dental experiences. 
Social media can be used for professional networking and positive self-promotion. Healthcare professionals should utilize social networking to educate and communicate with the community.

\section{Acknowledgment}

We thank the College of Dentistry Research Center (CDRC) for approving this study. This study didn't receive any financial support.

\section{Conflict of Interest}

The authors declare that they have no conflicts of interest related to this research.

\section{References}

1. Thackeray R, Neiger BL, Keller H (2012) Integrating Social Media and Social Marketing: A Four-Step Process. Health Promot Pract 13: 165168.

2. Fisher J, Clayton M (2012) Who Gives a Tweet: Assessing Patients' Interest in the Use of Social Media for Health Care. Worldviews Evid Based Nurs 9: 100-108.

3. Wylie L (2014) The social media revolution. Br J Midwifery 22: 502506.

4. WORLD IUITMEAIT. (2014).

5. BBC (2015) Saudi Arabia profile-Media.

6. The Statistics Portal (2018) Penetration of leading social networks in Saudi Arabia as of $3^{\text {rd }}$ quarter 2017.

7. Neville P, Waylen A (2015) Social media and dentistry: some reflections on e-professionalism. Bdj 218: 475-478.

8. Theobald AH, Wong BKJ, Quick AN, Thomson WM (2006) The impact of the popular media on cosmetic dentistry. N Z Dent 102: 58-63.

9. Christensen GJ (2002) Are prosthodontics a vital part of dentistry? J Am Dent Assoc 133: 647-648.

10. Hamm MP, Chisholm A, Shulhan J, Milne A, Scott SD, et al. (2013) Social media use among patients and caregivers: a scoping review. BMJ Open 3: e002819.

11. Hawn C (2009) Take two aspirin and tweet me in the morning: how Twitter, Facebook, and other social media are reshaping health care. Health Aff (Millwood) 28: 361-368.

12. Morris K (2011) Tweet, post, share--a new school of health communication. Lancet Infect Dis 11: 500-501.

13. Spallek H, O'Donnell J, Clayton M, Anderson P, Krueger A (2010) Paradigm shift or annoying distraction: emerging implications of web 2.0 for clinical practice. Appl Clin Inform 1: 96-115.

14. von Muhlen M, Ohno-Machado L (2012) Reviewing social media use by clinicians. J Am Med Inform Assoc 19: 777-781.
15. Brownstein CA, Brownstein JS, Williams DS $3^{\text {rd }}$, Wicks P, Heywood JA (2009) The power of social networking in medicine. Nat Biotechnol 27: 888-890.

16. Salem F, Mourtada R (2012) Social media in the Arab world: influencing societal and cultural change. Arab Soc media Rep 2: 1-29.

17. Duggan M (2013) It's a woman's (social media) world. Washington, DC.

18. Purcell K, Rainie L (2014) Technology's impact on workers. Pew Res Cent.

19. Askool SS (2012) The use of social media in Arab Countries: a case of Saudi Arabia. In: International Conference on Web Information Systems and Technologies 201-219.

20. Thackeray R, Neiger BL, Smith AK, Van Wagenen SB (2012) Adoption and use of social media among public health departments. BMC Public Health 12: 242.

21. Kolowitz BJ, Lauro GR, Venturella J, Georgiev V, Barone M, et al. (2014) Clinical social networking--a new revolution in provider communication and delivery of clinical information across providers of care? J Digit Imaging 27: 192-199.

22. Neiger BL, Thackeray R, Van Wagenen SA, Hanson $\mathrm{CL}$, West JH, et al. (2012) Use of social media in health promotion: purposes, key performance indicators, and evaluation metrics. Health Promot Pract 13: 159-164.

23. McNab C (2009) What social media offers to health professionals and citizens. Bull World Health Organ 87: 566.

24. Fox S, Duggan M (2013) Health online 2013. Pew Internet Am Life Proj.

25. Eytan T, Benabio J, Golla V, Parikh R, Stein S (2011) Social media and the health system. Perm J 15: 71-74.

26. Fox S (2011) The social life of health information, 2011. Pew Internet Am Life Proj.

27. Zickuhr K (2010) Major trends in online activities. Pew Internet Am Life Proj.

28. Lenhart A, Purcell K, Smith A, Zickuhr K (2010) Social Media \& Mobile Internet Use among Teens and Young Adults. Millennials. Pew Internet Am Life Proj.

29. Pujazon-Zazik M, Park MJ (2010) To tweet, or not to tweet: gender differences and potential positive and negative health outcomes of adolescents' social internet use. Am J Mens Health 4: 77-85.

30. Williams AL, Merten MJ (2008) A review of online social networking profiles by adolescents: implications for future research and intervention. Adolescence 43: 253-274. 